\title{
Progression of Chronic Kidney Disease: Adrenergic Genetic Influence on Glomerular Filtration Rate Decline in Hypertensive Nephrosclerosis
}

\author{
Yuqing Chen ${ }^{j} \quad$ Michael S. Lipkowitz ${ }^{\mathrm{e}}$ Rany M. Salem ${ }^{\mathrm{a}}$ Maple M. Fung ${ }^{\mathrm{a}}$ \\ Vibha Bhatnagarc Manjula Mahata ${ }^{\mathrm{a}}$ Caroline M. Nievergelt ${ }^{\mathrm{b}}$ Fangwen Rao ${ }^{\mathrm{a}}$ \\ Sushil K. Mahata ${ }^{a, h}$ Nicholas J. Schork ${ }^{f}$ Pamela J. Hicks ${ }^{i}$ Donald W. Bowden ${ }^{i}$ \\ Barry I. Freedman ${ }^{i}$ Victoria H. Brophy ${ }^{g}$ Daniel T. O'Connor ${ }^{a, d, h}$ \\ for the AASK co-investigators

\begin{abstract}
${ }^{\mathrm{a}}$ Departments of Medicine, ${ }^{\mathrm{b}}$ Pharmacology, ${ }^{\mathrm{C}}$ Family and Preventive Medicine, and ${ }^{\mathrm{d}}$ Institute for Genomic Medicine, University of California at San Diego, La Jolla, Calif., ${ }^{e}$ Renal Division, Mount Sinai School of Medicine, New York, N.Y., fDepartment of Molecular and Experimental Medicine, the Scripps Research Institute, La Jolla, Calif.,

gHuman Genetics Department, Roche Molecular Systems, Alameda, Calif., hVA San Diego Healthcare System, San Diego, Calif., and 'Wake Forest University School of Medicine, Winston-Salem, N.C., USA; 'ं Renal Division, Peking University First Hospital, Beijing, China
\end{abstract}

\section{Key Words}

Adrenergic genetic influence - African-American Study of Kidney Disease $\cdot$ Chronic kidney disease $\cdot$ End-stage renal disease $\cdot$ Glomerular filtration rate $\cdot$ Hypertensive nephrosclerosis

\begin{abstract}
Background: African-Americans are likely to develop hypertension and hypertensive nephrosclerosis. This grave prognosis, coupled with familial aggregation of end-stage renal disease (ESRD) in Blacks, prompts a search for genetic risk factors for ESRD. Recent evidence implicates a crucial role for the sympathetic nervous system in progressive renal disease. Methods: We used the African-American Study of Kidney Disease to probe whether $\beta_{2}$-adrenergic receptor (ADRB2) predicts glomerular filtration rate (GFR) decline rate. A total of 580 participants were included. Baseline GFR was $51.2 \pm 0.5 \mathrm{ml} / \mathrm{min} / 1.73 \mathrm{~m}^{2}$. Subjects were randomized in a $2 \times 3$ block design: to intensively lowered (MAP $\leq 92$
\end{abstract}

\section{KARGER}

Fax +4161306 1234 E-Mail karger@karger.ch www.karger.com
두 2010 S. Karger AG, Basel

Accessible online at: www.karger.com/ajn $\mathrm{mm} \mathrm{Hg}$ ) versus 'usual' (MAP $=102-107 \mathrm{~mm} \mathrm{Hg}$ ) blood pressure goal groups, and also divided by three randomized antihypertensive drugs (ramipril, metoprolol, or amlodipine). We scored 4 SNPs at the ADRB2 locus. Results: Haplotypes at ADRB2 predicted chronic GFR decline rate, GFR declined more slowely in individuals with haplotype-1 $(-804 \mathrm{G} \rightarrow 173 \mathrm{~T} \rightarrow 16 \mathrm{Gly} \rightarrow 27 \mathrm{Gln})$, and faster in those who carried haplotype-3 $(-804 \mathrm{G} \rightarrow 173 \mathrm{~T} \rightarrow 16 \mathrm{Arg} \rightarrow 27 \mathrm{Gln})$. ADRB2 genotype interacted with antihypertensive drug class to influence GFR slope ( $p=0.001-0.037$ ). We extended our findings to an independent case/control sample of Black hypertensive ESRD, in which we found that variant Gly16Arg that tagged the GFR slope-determining ADRB2 haplotype also conferred risk for the ESRD trait in Blacks. Conclusions: The GFR decline/progression rate in hypertensive renal disease is controlled in part by genetic variation within the adrenergic pathway.

Copyright $\odot 2010$ S. Karger AG, Basel

Y.C. and M.S.L. contributed equally to this work. 


\section{Introduction}

Hypertension is a leading reported cause of end-stage renal disease (ESRD) in the United States, and AfricanAmericans are $\sim 6$ times more likely to develop ESRD attributed to hypertension than Whites [1]. This unfavorable prognosis, coupled with familial aggregation of ESRD in Blacks $[2,3]$, prompts investigation of the genetic risk for this syndrome [4-7].

A role for the sympathetic nervous system in progression of renal failure is increasingly understood. Activation of renal afferent chemo- and mechanoreceptors may trigger neural events in/from damaged kidneys [8,9]. Increased efferent sympathetic traffic contributes to hypertension in animals [8] and patients with renal disease [10, 11]. Even at sub-antihypertensive doses, the adrenergic outflow inhibitor moxonidine ameliorates progressive renal damage [12]. Accumulating reports indicate that both hypertension and microalbuminuria are associated with allelic variants in the adrenergic pathway, including catecholamine biosynthetic enzymes and adrenergic receptors [13-18]; thus we hypothesized that such variants would also influence the rate of progression of chronic kidney disease.

The NIDDK AASK trial focused on a cohort with progressive hypertensive nephropathy, in which glomerular filtration rate (GFR) of each participant was measured every 3-6 months for 3-5 years [19]. A pilot study was performed to assess the underlying lesions in eligible participants through renal biopsy [20]. Both blood pressure (BP) goal and antihypertensive therapies were considered in the AASK $3 \times 2$ block design; thus environmental (drug and goal) exposures were appropriately balanced. Therefore the AASK trial provides a unique opportunity for research on genetic factors contributing to chronic renal functional decline. We hypothesized that the GFR decline rate measured in this population is subject to genetic determination, and common variants within adrenergic pathway genes may predict GFR decline rate.

\section{Methods}

\section{Subjects}

Primary Studies in African-American Study of Kidney

Disease and Hypertension (AASK) Subjects

Subjects were from the AASK Study, a 21-center randomized, controlled prospective trial that has been described previously $[19,21]$. Briefly, participants were 18 - to 70 -year-old self-identified African-Americans with hypertension, and a clinical diagnosis of hypertensive renal disease, documented by an initial GFR (by $\left.{ }^{125} \mathrm{I}\right]$-iothalamate clearance) between 20 and $65 \mathrm{ml} / \mathrm{min} / 1.73 \mathrm{~m}^{2}$, urinary protein to creatinine ratio $<2.5 \mathrm{~g} / \mathrm{g}$, and no other identified causes of renal insufficiency. Based on a $3 \times 2$ factorial design, participants were randomized to one of two goal BP ranges (half to a 'usual' mean arterial pressure goal of 102-107 mm Hg, or half to an intensively lowered mean arterial pressure goal of $\leq 92 \mathrm{~mm} \mathrm{Hg}$ ), and to double-blinded treatment with 1 of 3 antihypertensive drug classes ( $40 \%$ to $\beta$-blockade with metoprolol, $50-200 \mathrm{mg} /$ day; $40 \%$ to ACE inhibition with ramipril, $2.5-10 \mathrm{mg} /$ day, or $20 \%$ to calcium channel blockade with amlodipine, 5-10 $\mathrm{mg} /$ day). If the BP goal was not achieved while the participants were taking the study drug, and the dosage of each drug was increased to the maximum tolerated dose, additional unmasked drugs were added in the following recommended order: furosemide, doxazosin mesylate, clonidine hydrochloride, hydralazine hydrochloride, and minoxidil [21].

GFR was assessed by renal clearance of $\left[{ }^{125} \mathrm{I}\right]$-iothalamate at baseline twice, then at 3 and 6 months, and then every 6 months thereafter. Serum and urine creatinine and protein were measured by a central laboratory at 6-month intervals.

In previous reports from the AASK trial [22], initial degree of proteinuria was a strong predictor of GFR decline as well as the response of GFR to particular medications; indeed, the benefit of ACE inhibition to progression of renal disease was confined to a subgroup with less proteinuria [22]. Therefore, SNPs contributing to GFR slope were analyzed in the subgroup with baseline urinary protein/creatinine ratio (Pro_Cr) $\leq 0.22 \mathrm{~g} / \mathrm{g}(\mathrm{n}=580)$, as previously described [22]. The value of $0.22 \mathrm{~g} / \mathrm{g}$ corresponds to a urine protein excretion of $\sim 300 \mathrm{mg}$ /day, and divides the $\sim 2 / 3$ of patients with the lowest ('normal' range) proteinuria from the $1 / 3$ with highest proteinuria (the Pro_Cr parameter is skewed towards higher values, and inversely associated with initial GFR).

We were able to ascertain, consent, and prepare genomic DNA from blood leukocytes obtained from the participants in this study. Each subject gave informed, written consent to the local institutional review boards. They were aged from 20 to 70 years, 348 males and 232 females, with a baseline GFR of $51.2 \pm 0.5 \mathrm{ml} /$ $\min / 1.73 \mathrm{~m}^{2} .291$ participants were in the intensively lowered BP goal group, and 289 in the 'usual' BP goal group. When divided by randomized antihypertensive drug regimen, 239 participants received ramipril, 232 metoprolol and 109 amlodipine. The AASK subset reported here $(\mathrm{n}=580)$ did not differ from the complete AASK cohort $[19,22,23]$ in age $(p=0.408)$, sex $(p=0.714)$, initial/ entry BP (SBP p = 0.09, DBP $\mathrm{p}=0.97)$, initial GFR ( $\mathrm{p}=0.09)$, initial urine protein/creatinine $(\mathrm{p}=0.537-0.990$, calculated separately in different BP goal and drug groups), or overall rate of progression of renal disease (chronic/post-3 month GFR slope, $\mathrm{p}=0.9146$ ).

The primary analysis here is based on the chronic rate of change in GFR. The GFR slope was calculated separately during the first 3 months following randomization (acute slope) and then from 3 months and thereafter (chronic slope); the chronic slope was used as the primary outcome in this study. The acute and chronic phases were distinguished because previous studies indicated that the AASK interventions (especially calcium channel blockade) have acute effects on GFR that may differ from their long-term effects on disease progression [21, 24]. 
Table 1. ADRB2 gene variants for this association study (a) and haplotypes at ADRB2 in the AASK samples: effects on GFR decline rate (b)

a $A D R B 2$ gene variants

\begin{tabular}{lllll}
\hline Gene name (variant) & Protein product & Ref. SNP & $\begin{array}{c}\text { Location } \\
\text { Minor allele } \\
\text { (frequency) }\end{array}$ \\
\hline ADRB2 (G-804A) & $\beta_{2}$-adrenergic receptor & rs2053044 & promoter & A (0.4235) \\
ADRB2 (T173C) & $\beta_{2}$-adrenergic receptor & rs1042711 & $5^{\prime}$-UTR & C (0.1645) \\
ADRB2 (Gly16Arg) & $\beta_{2}$-adrenergic receptor & rs1042713 & coding & Arg (0.481) \\
ADRB2 (Gln27Glu) & $\beta_{2}$-adrenergic receptor & rs1042714 & Glu (0.175) \\
\hline
\end{tabular}

The minor allele of a biallelic SNP is the less common allele observed in this population of AASK. The minor allele nucleotide ( $\mathrm{A}$ = adenine; $\mathrm{G}$ = guanine; $\mathrm{C}=$ cytosine, $\mathrm{T}=$ thymine) or amino acid residue and its frequency are given for each SNP. 'Gene location' is the domain (e.g. coding region or intron) in which the SNP is located. All SNPs are labeled as major allele, followed by position, and followed by minor allele. Coding region SNPs resulted in non-synonymous change of amino acid, only protein residues and amino acid codon position are shown; while synonymous change of amino acid, numbers are shown as base pairs downstream $(+n)$ from the cap site and alleles as nucleotides. SNPs in the promoter are labeled by the number of base pairs $(-n)$ upstream from the cap (transcription initiation) site. SNPs in the $5^{\prime}$-UTR, introns and $3^{\prime}$-UTR are labeled by the number of base pairs downstream $(+n)$ from the cap site. SNP ID is the unique identifier in the public dbSNP database (http://www.ncbi.nlm. nih.gov/SNP).

b Haplotypes at ADRB2 in the AASK samples

\begin{tabular}{|c|c|c|}
\hline Gene (SNPs for haplotype inference) & $\begin{array}{l}\text { Haplotypes: } \\
\text { allele combination (freq.) }\end{array}$ & $\begin{array}{l}\text { Diploid haplotype pairs: } \\
\text { haplotype combination }\end{array}$ \\
\hline ADRB2 $(\mathrm{G}-804 \mathrm{~A} \rightarrow \mathrm{T} 173 \mathrm{C} \rightarrow$ Gly16Arg $\rightarrow$ Gln27Glu $)$ & 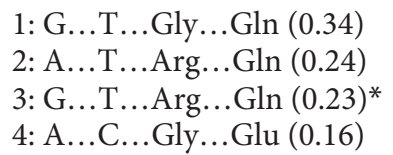 & $\begin{array}{l}\text { 1: haplotype-1, haplotype- } 2 \\
2: \text { haplotype- } 1 \text {, haplotype- } 3 * \\
3: \text { haplotype- } 2 \text {, haplotype- } 3\end{array}$ \\
\hline
\end{tabular}

Frequencies are based on the number of haplotype copies present in the entire sample.

* Haplotypes or pairs observed to have significant effects on GFR decline rate.

Extension: Case/Control Sample for Black Hypertensive ESRD

The extension sample consisted of 301 Black hypertensionassociated ESRD cases and 305 Black controls, ascertained from North Carolina; ESRD cases were ascertained from dialysis facilities after a clinical diagnosis of hypertension-associated ESRD and absence of diabetes, based on diagnosis by treating physician and review of medical charts. Healthy controls were sampled from the general Black population. Cases and controls differed in age $(\mathrm{p}<0.001)$, cases slightly older at $54.6 \pm 0.75$ years and 50.2 \pm 0.58 years for controls. Sex did not differ significantly between groups ( $\mathrm{p}<0.862) ; 56 \%$ of cases and $55.3 \%$ of controls were male. BMI was intensively lowered $(\mathrm{p}<0.001)$ in cases $(26.5 \pm 0.42)$ compared to controls ( $29.4 \pm 0.39$ ), as expected for ESRD. Controls reported normal kidney function and denied a family history of renal disease. These study subjects were born in the southeastern United States and resided in North Carolina [25].

Genomics

Single nucleotide polymorphisms (SNPs) were obtained from public SNP databases (http://www.ncbi.nih.nlm.gov/SNP) or dis- covered by resequencing (table 1a) [13]. Genomic DNA was typed using a matrix-assisted laser desorption ionization time-of-flight (MALDI-TOF) mass spectrometry system developed by Sequenom according to a published protocol [26], by pyrosequencing [27], or by an immobilized probe approach [28], in which each DNA sample was amplified in a multiplex polymerase chain reaction using biotinylated primers. Each polymerase chain reaction product pool was then hybridized to a panel of sequence-specific oligonucleotide probes immobilized in a linear array. The colorimetric detection method was based on the use of streptavidinhorseradish peroxidase conjugate with hydrogen peroxide and $3,3^{\prime}, 5,5^{\prime}$-tetramethylbenzidine as substrates. Reproducibility of genotyping was verified with 50 blinded replicate samples. SNPs evaluated in this study had minor allele frequencies of $\geq 4 \%$, and all were in Hardy-Weinberg equilibrium $(p>0.05)$.

Statistical Analyses

Haplotype Inference. Typing 4 common variants at ADRB2 allowed the inference of haplotypes from unphased diploid genotypes by the HAP imperfect phylogeny method (version 3.0) [29]. 

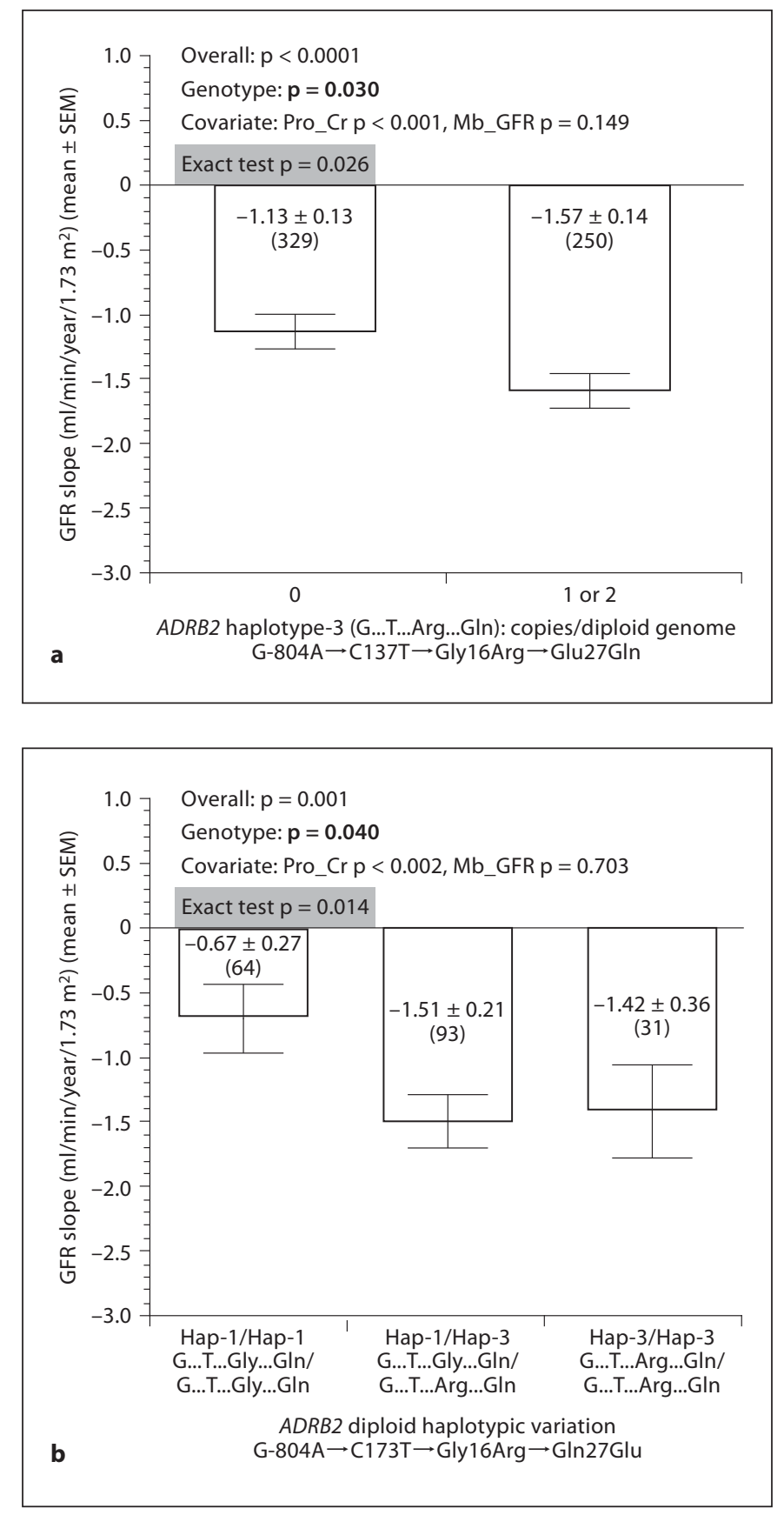

Fig. 1. Genetic variation at $A D R B 2$ : effects on GFR decline rate. Variants listed in table la are plotted here. GFR slope indicates GFR decline rate after 3 months. Gene effects on GFR slope were determined by one-way ANOVA; covariates included Pro_Cr, $\mathrm{Mb}$ GFR, drug group and BP goal group. Numbers in parentheses ( $\mathrm{n}$ ) indicate the $\mathrm{n}$ for that observation. $\mathrm{p}$ values for Pro_Cr and Mb_GFR are shown. Neither drug nor BP goal was significant in these analyses ( $p>0.05)$. a Haplotype-3. Effects of copy number $(0,1,2$ /genome $)$ on GFR slope $(n=579)$. b Diploid haplotype pairs composed of haplotype-1 and haplotype-3. n declines to 188 , since subjects carrying other haplotypes ( 2 or 4 ) as heterozygotes or homozygotes are excluded from this analysis.
Progression (Chronic Slope) of GFR Loss. One-way ANOVA determined the significance of haplotype effects on chronic (after 3 months on drug) GFR decline slope ( $\mathrm{ml} / \mathrm{min} / 1.73 \mathrm{~m}^{2} /$ year). Twoway ANOVA (covariates: Pro_Cr and Mb_GFR) assessed interaction effects of drug or BP goal with SNPs on GFR slope. Statistical Package for the Social Sciences, Version 11.0 (SPSS, Inc., Chicago, Ill., USA) was used. HAP (version 3.0) was used to impute haplotypes from diploid SNP genotypes for each individual [29].

Exact Test. An exact test is a type of statistical significance test in which a reference distribution is obtained by calculating all possible values of the test statistic under rearrangements of the labels on the observed data points. Resampling was performed with 'Resampling Stats Excel add-in version 3.2' (http://www. resample.com/content/software/excel/index.shtml). GFR decline rate values were independently permutated 1,000 times to generate an empirically derived distribution of test statistics (e.g. ANOVA F test statistics). The observed test statistics were compared with the empirically derived distributions of test statistics to derive $\mathrm{p}$ values.

Population Admixture. African-Americans represent an admixed population with genetic contributions from both African and European biogeographic origins [30]. In order to confirm that AASK individuals with or without trait-associated genotypes were of comparable overall genetic background, and the observed associations were not simply an artifact of differential admixture between higher and lower GFR decline rate, GAMOVA (generalized analysis of molecular variance) [31] was used to test for and quantify the relationship between the overall genetic background of the subjects and quantitative phenotype GFR decline rate (chronic GFR slope), with an IBS (identity-by-state) distance matrix based on genotypes at 126 biallelic markers. The admixture analysis was done in all individuals. The population admixture in North Carolina has been reported [25].

\section{Results}

\section{Primary Studies in AASK Subjects}

SNP Genotyping, Haplotypes, and GFR Slope. We typed 4 SNPs spanning ADRB2 (promoter, 5'-UTR, and coding region), giving rise to 4 common haplotypes and 3 diploid haplotype pairs (table $1 \mathrm{~b}$ ). ADRB2 variants Gly16Arg and Glu27Gln have been associated with hypertension [32], while G-804A and C173T are in the functional proximal promoter region and 5'-UTR [33]. GFR declined more slowly in individuals with haplotype $-804 \mathrm{G} \rightarrow 173 \mathrm{~T} \rightarrow 16 \mathrm{Gly} \rightarrow 27 \mathrm{Gln}$ (haplotype-1), and faster in those who carried $-804 \mathrm{G} \rightarrow 173 \mathrm{~T} \rightarrow 16 \mathrm{Arg} \rightarrow 27 \mathrm{Gln}$ (haplotype-3) (fig. 1a, b).

Effect of Antihypertensive Medication on Genetic Associations: ADRB2-by-Drug Interactions. We first explored whether diploid genotypes were equally distributed among the three drug groups; in $3 \times 3$ genotypeby-drug contingency tables, there was no deviation from the null expectation for the significant genotypes or hap- 
Table 2. Summary of gene-by-drug interactions on GFR decline rate

\begin{tabular}{ll}
\hline Gene variants & Two-way ANOVA \\
\hline ADRB2_Gln27Glu & $0.037(\mathrm{p}<0.05)$ \\
ADRB2_HAP1 & $0.001(\mathrm{p}<0.05)$ \\
ADRB2_HAP3 & $0.020(\mathrm{p}<0.05)$ \\
ADRB2_DIP2 & $0.004(\mathrm{p}<0.05)$ \\
\hline
\end{tabular}

Analyses were done in AASK subjects with urine protein/ creatinine ratio $\leq 0.22 \mathrm{~g} / \mathrm{g}$. All significant SNPs which interacted with drugs are listed. ADRB2_HAP1 = ADRB2 haplotype-1 $(-804 \mathrm{G} \rightarrow 173 \mathrm{~T} \rightarrow 16 \mathrm{Gly} \rightarrow 27 \mathrm{Gln}) ;$ ADRB2_HAP3 $=$ ADRB2 haplotype-3 $\quad(-804 \mathrm{G} \rightarrow 173 \mathrm{~T} \rightarrow 16 \mathrm{Arg} \rightarrow 27 \mathrm{Gln}) ; \quad A D R B 2 \_\mathrm{DIP} 2=$ ADRB2 diploid haplotype combination-2 (haplotype-1, haplotype-3).

lotypes $\left(\chi^{2}=0.011-5.592 ; \mathrm{p}=0.071-0.99\right)$. Four SNPs or haplotypes at $A D R B 2$ displayed significant gene-by-drug interactions on GFR decline rate (table 2).

Extension to a Case/Control Sample: Black Hypertensive ESRD. We wondered if the same variants that accelerated progression of renal disease in AASK also influenced overall hypertensive ESRD risk/susceptibility in a case/control setting. Our ESRD studies targeted $A D R B 2$, since polymorphism here accounted for up to $\sim 39 \%$ of the interindividual variation in GFR decline slope.

At ADRB2, we focused on individual variant Gly16Arg, since that amino acid substitution uniquely 'tagged' the difference between the trait-associated haplotype pairs, with the Arg allele predicting faster downward GFR slope. In the hypertensive ESRD case/control sample (fig. 2), the Arg allele was more prominent in cases than controls $(p=0.019)$, and the difference persisted after permutation $(\mathrm{p}=0.029)$.

Genetic Admixture. In the AASK subjects reported here, 126 biallelic markers were genotyped. GAMOVA analysis indicated that people with similar predictor variables (GFR slope, $\mathrm{ml} / \mathrm{min} / 1.73 \mathrm{~m}^{2} /$ year) were not genetically more related to each other than expected by chance alone, in the group with lesser proteinuria $(\mathrm{p}=0.87)$. Therefore, the specific adrenergic allele and haplotype frequency differences in GFR trait means that we observed cannot be attributed to differential admixture between the higher and lower GFR decline rate groups.

In the California subjects, the Pritchard-18 method, testing differences between cases and controls, did not reveal differential admixture $\left(\chi^{2}=45.08,46\right.$ d.f., $\mathrm{p}=$ 0.511). Likewise, a 'genetic distance' measure (Slatkin's

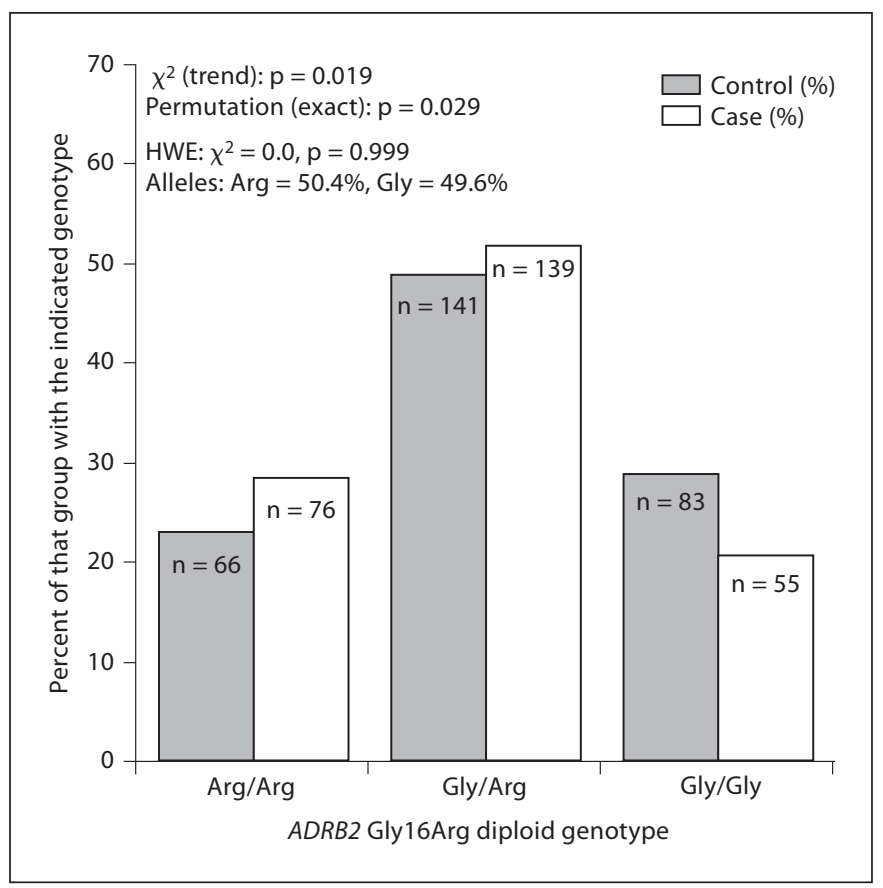

Fig. 2. $A D R B 2$ variant Gly16Arg: risk/susceptibility genotype for Black hypertensive ESRD. The figure shows ADRB2 Gly16Arg diploid genotype frequency distributions between hypertensive ESRD cases and healthy controls. All subjects were AfricanAmerican (by self-identification).

linearized FST) calculated using Arlequin-19 failed to reveal differences between cases and controls (FST = $-0.00099, \mathrm{p}<0.721)$. Therefore, the observed CHGA allele and haplotype frequency differences cannot be attributed to differential admixture between the case and control groups [25].

\section{Discussion}

\section{Overview}

The autonomic nervous system is a key determinant of BP and renal function. Earlier studies showed that coldinduced stress stimulates the sympathetic nervous system, causing hypertension, proteinuria and renal pathology in rats [34], and infused catecholamines cause GFR decline and proteinuria in man [35]. African-Americans, a segment of the population at increased risk for hypertension and nephrosclerosis, display exaggerated autonomic responses to environmental stressors [36-39]. Although recent genomic studies of hypertension-associated renal disease in African-Americans indicate a major 
role for genetic variation at the MYH9 (non-muscle myosin isoform) locus [40], adrenergic genetic determinants of renal dysfunction in this population have also been documented [41, 42].

\section{Adrenergic Hereditary Mechanisms}

After initial renal injury, progressive loss of renal function reflects maladaptive changes in the kidney, such as glomerular hyperfiltration. The sympathetic nervous system regulates renal as well as systemic hemodynamics. Mühlbauer et al. [43] reported that amino acid-induced glomerular hyperfiltration was abolished by bilateral renal denervation, documenting a role of the sympathetic system in regulating GFR. Selective pharmacologic reduction of sympathetic activity attenuates progression of chronic renal disease [12]. A role for heredity in control of glomerular hemodynamics was also suggested by our observation [44] that genetic risk (family history) of hypertension predicts the GFR response to amino acids.

\section{$\beta$-Adrenergic Receptors}

In this study, we found that ADRB2 variants affected GFR slope. At ADRB2, the trait-associated haplotypes 1 (G-T-Gly-Gln; slower GFR decline) and 3 (G-T-Arg-Gln; faster GFR decline) differed only at position Glyl6Arg. The Gly16 variant undergoes enhanced agonist-promoted downregulation, whereas the Glu27 variant is largely resistant to such downregulation; Gly16 dominates functionally when both SNPs are concomitantly present [45]. Since the Gly16 variant is more prone to desensitization, it could be expected that its steady-state agonist responsiveness is lower under physiological circumstances due to tonic exposure to endogenous catecholamines; enhanced sympathetic activity in hypertensive subjects might further promote such downregulation. This consideration yields the working hypothesis that the Gly16 variant mechanistically caused less dilation, thereby decreasing glomerular hyperfiltration. Thus many observers find that Gly16 is associated with hypertension [32], while in our study a haplotype including Gly16 predicts slower GFR decline rate. In the setting of systemic hypertension and catecholamine excess, the desensitizationresistant Arg16 variant might thereby result in afferent arteriolar dilation, with consequent hyperfiltration, predisposing to more rapid long-term GFR decline. Indeed, Nakamura et al. [46] found that $\beta_{2}$-receptor agonist exposure resulted in a decline of GFR in rats with $\beta_{2}$-receptor overexpression, an observation compatible with our findings and hypothesis. In this study, we did not measure the sympathetic nerve activity. Masuo et al. [47] re- ported that Gly16 allele was associated with weight gain, BP elevation and higher plasma norepinephrine levels. However, Masuo's group studied 160 young non-obese, normotensive men, which is quite different to our population.

Previously we found that $A D R B 1$ [42] genetic variants affected GFR slope. Both ADRB1 and ADRB2 are expressed in renal arterial smooth muscle cells, while $A D R B 1$ is also detected in mesangial cells [48]. Catecholamines acting on these receptors would dilate renal arterioles and mesangial cells, thereby regulating not only renal blood flow but also filtration surface, consequently altering glomerular capillary hydrostatic pressure, a wellknown force in progressive renal disease [49]. Genetic variation at $A D R B 1$ and $A D R B 2$ might affect GFR decline rate by several mechanisms: altering receptor-binding affinity, agonist coupling to effectors, or desensitization $[45,50]$.

Both ADRB1 and ADRB2 signal by increasing the second messenger cAMP; thus, the GFR decline altering polymorphisms we identified at $A D R B 1$ [42] and $A D R B 2$ may converge on a focal point of intracellular signal transduction: cAMP. Since cAMP mediates $\beta$-receptoractivated vasodilation, changes in CAMP within renal arterioles and mesangial cells are likely to be critical to control of glomerular function.

Previously we also found that genetic variation at chromogranin A (CHGA), which plays crucial roles in sympathetic activity, predicted GFR in healthy individuals, as well as progression of hypertensive nephrosclerosis [41]. Involvement of these three genes (CHGA, ADRB1, and $A D R B 2$ ) suggests novel pathophysiological links between the adrenergic system and chronic renal injury.

\section{Extension of Adrenergic Associations to an}

Independent Hypertensive ESRD Group

An exact replication of the AASK trial is unlikely, given the scope of its duration, size, intensity, complexity, and expense. Nonetheless, we sought confirmation of the role of adrenergic polymorphism in hypertensive ESRD, this time turning to the case/control design. Here we considered $A D R B 2$, since genetic variation at that locus influenced GFR slope. ADRB2 haplotypes that altered GFR slope differed only at Gly16Arg, with the 16Arg-bearing haplotype-3 predicting faster GFR decline. We therefore 'tagged' ADRB2 with the Gly16Arg variant, in an African-American hypertensive ESRD case/control study [25]. Gly16Arg influenced risk for hypertensive ESRD in Blacks ( $p=0.019$; fig. 2); indeed, the transition from control to case status resulted in a 'flip' in the major (most 
frequent) allele at codon 16, from Gly (control) to Arg (case). Since the codon 16Arg variant is relatively resistant to agonist-mediated desensitization [45], one might predict that 16Arg allele carriers would exhibit afferent arteriolar dilation, with consequent glomerular capillary hypertension, predisposing to renal injury in the long term.

\section{Conclusions and Perspectives: Pathways}

We conclude that GFR decline rate in progressive renal disease is governed in part by common genetic variation within the adrenergic pathway. Thus, GFR decline (or progression of chronic kidney disease) seems to be a polygenic trait, involving pathway contributions from
$A D R B 2, A D R B 1$, and $C H G A$. Our results suggest new strategies for probing the role and actions of the pathway within this setting.

\section{Acknowledgements}

We appreciate the support of the NIH/NCMHD-sponsored (MD000220) EXPORT Minority Health Center, the NIH/NCRRsponsored (RR00827) General Clinical Research Center, and the National Institutes of Health, Department of Veterans Affairs. Y. Chen is supported by a fellowship from the International Society of Nephrology.

\section{References}

1 Rahman M, Douglas JG, Wright JT Jr: Pathophysiology and treatment implications of hypertension in the African-American population. Endocrinol Metab Clin North Am 1997;26:125-144.

-2 Ferguson R, Grim CE, Opgenorth TJ: A familial risk of chronic renal failure among Blacks on dialysis? J Clin Epidemiol 1988;41: 1189-1196.

- 3 Freedman BI, Spray BJ, Tuttle AB, Buckalew VM Jr: The familial risk of end-stage renal disease in African-Americans. Am J Kidney Dis 1993;21:387-393.

4 Freedman BI, Yu H, Anderson PJ, Roh BH, Rich SS, Bowden DW: Genetic analysis of nitric oxide and endothelin in end-stage renal disease. Nephrol Dial Transplant 2000;15: 1794-1800.

5 Schelling JR, Zarif L, Sehgal A, Iyengar S, Sedor JR: Genetic susceptibility to end-stage renal disease. Curr Opin Nephrol Hypertens 1999;8:465-472.

-6 Yu H, Bowden DW, Spray BJ, Rich SS, Freedman BI: Linkage analysis between loci in the renin-angiotensin axis and end-stage renal disease in African-Americans. J Am Soc Nephrol 1996;7:2559-2564.

7 Yu H, Song Q, Freedman BI, Chao J, Chao L, Rich SS, Bowden DW: Association of the tissue kallikrein gene promoter with ESRD and hypertension. Kidney Int 2002;61:1030-1039.

-8 Campese VM, Kogosov E: Renal afferent denervation prevents hypertension in rats with chronic renal failure. Hypertension 1995;25: 878-882.

9 DiBona GF, Sawin LL: Effect of renal nerve stimulation on $\mathrm{NaCl}$ and $\mathrm{H}_{2} \mathrm{O}$ transport in Henle's loop of the rat. Am J Physiol 1982; 243:F576-F580

10 Converse RL Jr, Jacobsen TN, Toto RD, Jost CM, Cosentino F, Fouad-Tarazi F, Victor RG: Sympathetic overactivity in patients with chronic renal failure. N Engl J Med 1992;327: 1912-1918.
Hansen J, Victor RG: Direct measurement of sympathetic activity: new insights into disordered blood pressure regulation in chronic renal failure. Curr Opin Nephrol Hypertens 1994;3:636-643.

12 Amann K, Rump LC, Simonaviciene A, Oberhauser V, Wessels S, Orth SR, Gross ML, Koch A, Bielenberg GW, Van Kats JP, Ehmke H, Mall G, Ritz E: Effects of low dose sympathetic inhibition on glomerulosclerosis and albuminuria in subtotally nephrectomized rats. J Am Soc Nephrol 2000;11:14691478.

13 Bao X, Mills PJ, Rana BK, Dimsdale JE, Schork NJ, Smith DW, Rao F, Milic M O'Connor DT, Ziegler MG: Interactive effects of common $\beta_{2}$-adrenoceptor haplotypes and age on susceptibility to hypertension and receptor function. Hypertension 2005;46:301-307.

14 Lee YW, Oh VM, Garcia E, Taylor EA, Wu H Yap EP, Kazeem GR, Caulfield MJ, Munroe PB: Haplotypes of the $\beta_{2}$-adrenergic receptor gene are associated with essential hypertension in a Singaporean Chinese population. J Hypertens 2004;22:2111-2116.

15 Ranade K, Shue WH, Hung YJ, Hsuing CA, Chiang FT, Pesich R, Hebert J, Olivier M, Chen YD, Pratt R, Olshen R, Curb D, Botstein D, Risch N, Cox DR: The glycine allele of a glycine/arginine polymorphism in the $\beta_{2}$-adrenergic receptor gene is associated with essential hypertension in a population of Chinese origin. Am J Hypertens 2001;14 1196-1200.

16 Rao F, Wessel J, Wen G, Zhang L, Rana BK, Kennedy BP, Greenwood TA, Salem RM, Chen Y, Khandrika S, Hamilton BA, Smith DW, Holstein-Rathlou NH, Ziegler MG, Schork NJ, O'Connor DT: Renal albumin excretion: twin studies identify influences of heredity, environment, and adrenergic pathway polymorphism. Hypertension 2007;49: 1015-1031
17 Sharma P, Hingorani A, Jia H, Ashby M, Hopper R, Clayton D, Brown MJ: Positive association of tyrosine hydroxylase microsatellite marker to essential hypertension. Hypertension 1998;32:676-682.

18 Zhang L, Rao F, Wessel J, Kennedy BP, Rana BK, Taupenot L, Lillie EO, Cockburn M, Schork NJ, Ziegler MG, O'Connor DT: Functional allelic heterogeneity and pleiotropy of a repeat polymorphism in tyrosine hydroxylase: prediction of catecholamines and response to stress in twins. Physiol Genomics 2004;19:277-291.

19 Wright JT Jr, Kusek JW, Toto RD, Lee JY, Agodoa LY, Kirk KA, Randall OS, Glassock R: Design and baseline characteristics of participants in the African-American Study of Kidney Disease and Hypertension (AASK) pilot study. Control Clin Trials 1996;17:3S$16 \mathrm{~S}$.

20 Fogo A, Breyer JA, Smith MC, Cleveland WH, Agodoa L, Kirk KA, Glassock R: Accuracy of the diagnosis of hypertensive nephrosclerosis in African-Americans: a report from the African-American Study of Kidney Disease (AASK) trial. AASK pilot study investigators. Kidney Int 1997;51:244252.

21 Agodoa LY, Appel L, Bakris GL, Beck G, Bourgoignie J, Briggs JP, Charleston J, Cheek D, Cleveland W, Douglas JG, Douglas M, Dowie D, Faulkner M, Gabriel A, Gassman J, Greene T, Hall Y, Hebert L, Hiremath L, Jamerson K, Johnson CJ, Kopple J, Kusek J, Lash J, Lea J, Lewis JB, Lipkowitz M, Massry S, Middleton J, Miller ER 3rd, Norris K, O'Connor D, Ojo A, Phillips RA, Pogue V, Rahman M, Randall OS, Rostand S, Schulman G, Smith W, Thornley-Brown D, Tisher CC, Toto RD, Wright JT Jr, Xu S: Effect of ramipril vs. amlodipine on renal outcomes in hypertensive nephrosclerosis: a randomized controlled trial. JAMA 2001;285:27192728 
-22 Wright JT Jr, Bakris G, Greene T, Agodoa LY, Appel LJ, Charleston J, Cheek D, DouglasBaltimore JG, Gassman J, Glassock R, Hebert L, Jamerson K, Lewis J, Phillips RA, Toto RD, Middleton JP, Rostand SG: Effect of blood pressure intensively lowering and antihypertensive drug class on progression of hypertensive kidney disease: results from the AASK trial. JAMA 2002;288:2421-2431.

-23 Wright JT Jr, Agodoa L, Contreras G, Greene T, Douglas JG, Lash J, Randall O, Rogers N, Smith MC, Massry S: Successful blood pressure control in the African-American Study of Kidney Disease and Hypertension. Arch Intern Med 2002;162:1636-1643.

- 24 Hall WD, Kusek JW, Kirk KA, Appel LJ, Schulman G, Agodoa LY, Glassock R, Grim C, Randall OS, Massry SG: Short-term effects of blood pressure control and antihypertensive drug regimen on glomerular filtration rate: The African-American Study of Kidney Disease and Hypertension Pilot Study. Am J Kidney Dis 1997;29:720-728.

25 Salem R, Cadman P, Chen Y, Rao F, Wen G, Hamilton B, Rana B, Smith D, Stridsberg M, Ward $\mathrm{H}$, Mahata M, Mahata S, Bowden D, Hicks P, Freedman B, Schork N, O'Connor DT: Chromogranin A polymorphisms are associated with hypertensive renal disease. J Am Soc Nephrol 2008;19:600-614.

-26 Buetow KH, Edmonson M, MacDonald R, Clifford R, Yip P, Kelley J, Little DP, Strausberg R, Koester H, Cantor CR, Braun A: High-throughput development and characterization of a genomewide collection of gene-based single nucleotide polymorphism markers by chip-based matrix-assisted laser desorption/ionization time-of-flight mass spectrometry. Proc Natl Acad Sci USA 2001; 98:581-584.

-27 Ahmadian A, Ehn M, Hober S: Pyrosequencing: history, biochemistry and future. Clin Chim Acta 2006;363:83-94.

28 Cheng S, Grow MA, Pallaud C, Klitz W, Erlich HA, Visvikis S, Chen JJ, Pullinger CR, Malloy MJ, Siest G, Kane JP: A multilocus genotyping assay for candidate markers of cardiovascular disease risk. Genome Res 1999;9:936-949.

-29 Halperin E, Eskin E: Haplotype reconstruction from genotype data using imperfect phylogeny. Bioinformatics 2004;20:18421849.
30 McKeigue PM, Carpenter JR, Parra EJ, Shriver MD: Estimation of admixture and detection of linkage in admixed populations by a bayesian approach: application to African-American populations. Ann Hum Genet 2000;64:171-186.

31 Nievergelt CM, Libiger O, Schork NJ: Generalized analysis of molecular variance. PLoS Genet 2007;3:e51.

32 Hahntow IN, Koopmans RP, Michel MC: The $\beta_{2}$-adrenoceptor gene and hypertension: is it the promoter or the coding region or neither? J Hypertens 2006;24:1003-1007.

-33 Johnatty SE, Abdellatif M, Shimmin L, Clark RB, Boerwinkle E: $\beta_{2}$-Adrenergic receptor $5^{\prime}$ haplotypes influence promoter activity. $\mathrm{Br} \mathrm{J}$ Pharmacol 2002;137:1213-1216.

34 Kanayama N, Tsujimura R, She L, Maehara $\mathrm{K}$, Terao T: Cold-induced stress stimulates the sympathetic nervous system, causing hypertension and proteinuria in rats. J Hypertens 1997;15:383-389.

35 King SE, Baldwin DS: Production of renal ischemia and proteinuria in man by the adrenal medullary hormones. Am J Med 1956; 20:217-224.

36 Calhoun DA, Mutinga ML, Collins AS, Wyss JM, Oparil S: Normotensive Blacks have heightened sympathetic response to cold pressor test. Hypertension 1993;22:801-805.

37 Light KC, Obrist PA, Sherwood A, James SA, Strogatz DS: Effects of race and marginally elevated blood pressure on responses to stress. Hypertension 1987;10:555-563.

38 Light KC, Sherwood A: Race, borderline hypertension, and hemodynamic responses to behavioral stress before and after $\beta$-adrenergic blockade. Health Psychol 1989;8:577595.

- 39 Parmer RJ, Cervenka JH, Stone RA, O'Connor DT: Autonomic function in hypertension. Are there racial differences? Circulation 1990;81:1305-1311.

40 Freedman BI, Hicks PJ, Bostrom MA, Cunningham ME, Liu Y, Divers J, Kopp JB, Winkler CA, Nelson GW, Langefeld CD, Bowden DW: Polymorphisms in the non-muscle myosin heavy chain 9 gene (MYH9) are strongly associated with end-stage renal disease historically attributed to hypertension in African-Americans. Kidney Int 2009;75:736745 .
41 Chen Y, Mahata M, Rao F, Khandrika S, Courel M, Fung MM, Zhang K, Stridsberg M, Ziegler MG, Hamilton BA, Lipkowitz MS, Taupenot L, Nievergelt C, Mahata SK, O'Connor DT: Chromogranin A regulates renal function by triggering Weibel-Palade body exocytosis. J Am Soc Nephrol 2009;20: 1623-1632.

-42 Fung MM, Chen Y, Lipkowitz MS, Salem RM, Bhatnagar V, Mahata M, Nievergelt CM, Rao F, Mahata SK, Schork NJ, Brophy $\mathrm{VH}, \mathrm{O}$ 'Connor DT: Adrenergic $\beta_{1}$-receptor genetic variation predicts longitudinal rate of GFR decline in hypertensive nephrosclerosis. Nephrol Dial Transplant 2009;24:36773686.

43 Mühlbauer B, Spohr F, Schmidt R, Osswald $\mathrm{H}$ : Role of renal nerves and endogenous dopamine in amino acid-induced glomerular hyperfiltration. Am J Physiol 1997;273:F144F149.

44 O'Connor DT, Tyrell EA, Kailasam MT, Miller LM, Martinez JA, Henry RR, Parmer RJ, Gabbai FB: Early alteration in glomerular reserve in humans at genetic risk of essential hypertension: mechanisms and consequences. Hypertension 2001;37:898-906.

45 Green SA, Turki J, Innis M, Liggett SB: Amino-terminal polymorphisms of the human $\beta_{2}$-adrenergic receptor impart distinct agonist-promoted regulatory properties. Biochemistry 1994;33:9414-9419.

- 46 Nakamura A, Niimi R, Imaizumi A, Yanagawa Y: Renal effects of $\beta_{2}$-adrenoceptor agonist and the clinical analysis in children. Pediatr Res 2007;61:129-133.

- 47 Masuo K, Katsuya T, Fu Y, Rakugi H, Ogihara T, Tuck ML: $\beta_{2}$ - and $\beta_{3}$-adrenergic receptor polymorphisms are related to the onset of weight gain and blood pressure elevation over 5 years. Circulation 2005;111: 3429-3434.

-48 Boivin V, Jahns R, Gambaryan S, Ness W, Boege F, Lohse MJ: Immunofluorescent imaging of $\beta_{1^{-}}$and $\beta_{2}$-adrenergic receptors in rat kidney. Kidney Int 2001;59:515-531.

- 49 Anderson S, Brenner BM: Intraglomerular hypertension: implications and drug treatment. Annu Rev Med 1988;39:243-253.

-50 Sandilands A, Yeo G, Brown MJ, O'Shaughnessy KM: Functional responses of human $\beta_{1}$-adrenoceptors with defined haplotypes for the common $389 \mathrm{R}>\mathrm{G}$ and $49 \mathrm{~S}>\mathrm{G}$ polymorphisms. Pharmacogenetics 2004;14: 343-349. 